\title{
Role of certifications in improving the quality of Education in Outcome Based Education
}

\author{
M.Madhavi ${ }^{1}$, G.Vishnu Murthy ${ }^{2}$ \\ ${ }^{1}$ CSE,Anurag Group of Institutions, Hyderabad. \\ ${ }^{2}$ CSE,Anurag Group of Institutions, Hyderabad. \\ ${ }^{1}$ mmadhavicse@cvsr.ac.in \\ ${ }^{2}$ hodcse@cvsr.ac.in
}

\begin{abstract}
Customary training frameworks don't furnish understudies with essential learning and abilities and satisfy the exhibition desires. OBE changes training into customized learning and empower training organizations to structure guidance models custom-made to learning inclinations of understudies. Certification has found its way into almost every industry for a reason: It helps advance the profession. Certification helps students evaluate potential new hires, analyze job performance, evaluate students and motivate them to enhance their skills and knowledge. Considering the role of certification our college has encouraged students to register for different courses online. This Paper gives a glimpse of certifications done by our students and how it has helped them to get placed in MNCs'.
\end{abstract}

Keywords: Certification, Rank sheet, Hacker Rank

\section{INTRODUCTION}

Training into customized learning and empowers training foundations to plan guidance models custom-made to the learning inclinations of understudies. OBE is developing at bewildering rates everywhere throughout the world. Each establishment has an extraordinary OBE system to create able understudies to take on an expert vocation after graduation. Very regularly, this information isn't productively caught and utilized in advanced education organizations.

It is dissipated in archives, spreadsheets, models, individuals' psyches and covered in desk work. Imagine a scenario where the connecting of educational program procedures could be all the more effectively caught in training foundations as advanced education programming mind maps that can be handled, actuated, shared and reused to make better learning results. Imagine a scenario in which there are better approaches to improve instruction quality.

The field of alternative education and training has generated a lot of buzz around itself

CSE,Anurag Group of Institutions, Hyderabad
Type "certifications in demand" in Google and you get millions of results with a fraction of a second. So, you must be wondering how relevant a certification is and how it will actually help your career. Isn't it?

There are always two sides to a story. Likewise, the tale of certifications is no different. On one hand, there are several certifications are just printed papers, to obtain which all you need to do is pass a yes/no test.

On the other hand, there are many other certifications that verify your knowledge and expertise and can definitely make a difference to your career. However, moving up the certifications ladder is not a cakewalk. In a long run, certification certainly benefits your career and helps you land better jobs as it proves your skills to your potential students.

\section{REASONS TO DO CERTIFICATION}

\subsection{Certifications improve career options}

If you are a fresh graduate from university or looking for a career change over then expertise or proven record of skills. Here, certifications can serve as the missing link. Certifications will validate your knowledge and skills in particular areas and provide you an edge over others during the employment process.

\subsection{Certifications removes gaps between knowledge and skills}

Many a time, we have seen that college graduates are not in sync with what the labor market needs. They have the theoretical knowledge of subjects but lack the skills to work for production-ready environments. This is where training programs and certifications come into play as they help in bridging the gap and facilitating the alignment of young professionals with the market. Certifications prove as a trusted framework to demonstrate that you are job ready. Both the training course as well as the certification aids to boost your career by making your expertise and skills relevant and accredited. 


\subsection{Short term Certification Courses}

The certification courses do not run for two or three years rather they just take a few days or a few months. Therefore, these are a good choice for those who have less time to spare and at the same time want to enrich their professional endeavor at a faster pace. Moreover, certification programs also offer hands-on training that lets you try and test the technologies and enhance your skills by participating in real-life scenarios.

\subsection{Certifications Exhibits commitment}

Certifications not only prove that you have the expertise required for the job or the project but certifications also showcase your commitment towards what you do, offering credible proof that you have common knowledge on the topic. Certifications show that you are fully committed to your career besides validating that you possess the latest information, and know-how of the tools when doing your job.

\subsection{Certification represents Specialization}

When you undergo a certification process, you get specialized in one particular technology as the course imparts specialized knowledge and equip with you the skills specific to that technology. Specialization opens new avenues in the job market as most students and companies seek specialists who can focus on one assignment in a perfect manner.

\subsection{Certifications create Opportunities}

Training and certifications do impact your career positively, in terms of financial benefits. According to a salary survey by PeopleCert, professionals who were holding IT certifications or added new skills through training were twice as likely as the overall average to see a salary raise of 11 percent or higher, and hikes appeared to be more pronounced for professionals who acquired a new certification within the prior 12 months of the appraisal.

\subsection{Certifications are quick Gateways}

The certification enables you to take a smarter approach to your profession and helps you move ahead faster. They provide a quick gateway to climbing up the corporate ladder, which otherwise, would have taken years to gain the experience and prove the skills to your superiors.

\section{Benefits of Certification}

- Increase a Competitive Advantage. Having preparing that your rivals don't can separate you when seeking after new business

- Execute Projects with Increased Efficiency

- Increment Your Earning Potential

- Update Your Knowledge and Skills

- Assemble Professional Credibility.

\section{Certifications in AGI}

In Anurag group of Institutions has started the process of certification from I Year of B.Tech .The certification process will be regarding the programming languages. I year students were trained with the programming concepts of the language. The certification has been practiced in Rank sheet .The analytical and problem solving skills of the students were improved by using Hacker Rank. Students have done the certifications in MS-Word and MS-power point. The department of CSE has encouraged students to join many number of technical clubs under which they are trained with technology and can obtain certification in the concerned technology.

The different clubs involved are Android, MALAI, IOT,NULL club. Students who have achieved certifications has achieved their success by attaining placement in MNC'S. The students have improved their programming with HACKER rank. Hacker Rank is the Ranking site where students will be awarded with rank by solving the problems in a specific area of Technology.

\section{Student Awards}

The students have been always awarded from the department who have achieved certification under the program called "CONVALLIS" in Fig 1.In this program the students who scored good rank in Hacker Rank and certification in Rank sheet will be awarded from the department with Certificate of appreciation and a badge of Excellence shown in Fig 1.

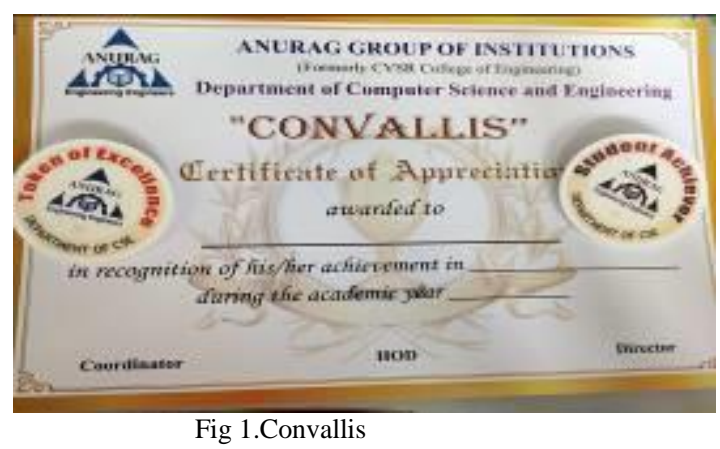

\section{Analysis of Certifications year wise}

Most of the students who have done their certification in different technologies have given their feedback that how this certification and ranking was helpful in their written examination for MNC's .Students who got placed in MNC's strongly recommended that certifications have helped them to solve most of the questions in the exam and helped them to grab the job in TCS.The problems solved in hacker rank has improved their skills of problem solving shown in Fig 2,3. 


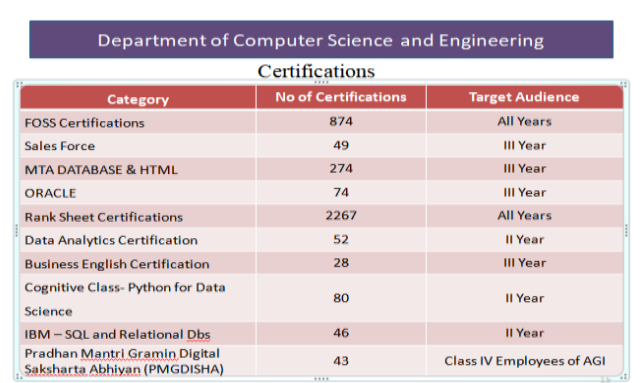

Fig 2.Certifications in Different Technologies

Department of Computer Science and Engineering

\begin{tabular}{|c|c|c|c|c|c|}
\hline \multicolumn{6}{|c|}{ Certifications - FoSS } \\
\hline Batch/Technology & \multicolumn{2}{|c|}{$\begin{array}{l}\text { Linux-Ubuntu } \\
\text { II and III year }\end{array}$} & \begin{tabular}{|l|} 
C \\
Programming \\
II year \\
\end{tabular} & \begin{tabular}{|l|} 
Java \\
III Year
\end{tabular} & $\begin{array}{l}\text { PHP \& } \\
\text { MySQL } \\
\text { IVYear }\end{array}$ \\
\hline 2015-2019 & & & & & 150 \\
\hline $2016-2020$ & 168 & & & 169 & \\
\hline 2017-2021 & 189 & & 198 & & \\
\hline No. of Certifications & 357 & & 198 & 169 & 150 \\
\hline Total Certifications & \multicolumn{5}{|c|}{874} \\
\hline \multicolumn{6}{|c|}{ Value Added Courses (VAC) Through CISCO } \\
\hline Batch/Technology & \begin{tabular}{|l|} 
IT \\
Essentials
\end{tabular} & IoT & $\begin{array}{l}\text { Programming } \\
\text { Essentials in C }\end{array}$ & $\begin{array}{l}\text { Cyber } \\
\text { Security }\end{array}$ & Python \\
\hline 2016-2020 & & & 206 & 209 & 224 \\
\hline $2017-2021$ & & 202 & 211 & & \\
\hline 2018-2022 & 1134 & & & & \\
\hline Total Certifications & & & 2186 & & \\
\hline
\end{tabular}

Fig 3.Year wise Certifications

The Department of CSE has done the certification program as mandatory to all the students from I B.Tech .Every Year number of certifications has improved and students has started showing enthusiasm in solving the problems and attaining certifications. The Certifications under Rank Sheet included in the Academic plan shown in Fig 4.
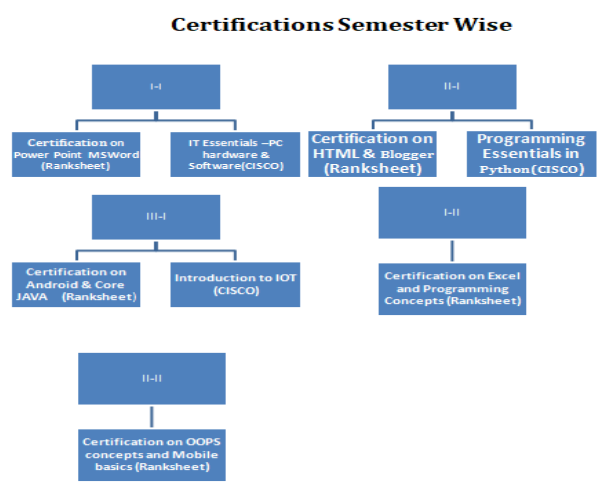

Fig 4.Semester wise certification plan

CSE Department has encouraged the students to do certifications in different technologies, which are listed below
- CISCO
- Oracle
- FOSS
- TASK
- VAC
- Rank sheet

The more certifications done by the students the more confident they become to achieve success in their education and career. It boosts their level of understanding and programming skills. As an achievement under android club 34 students have got certified in Rank sheet, which helped them to understand the technology shown in Fig 5.

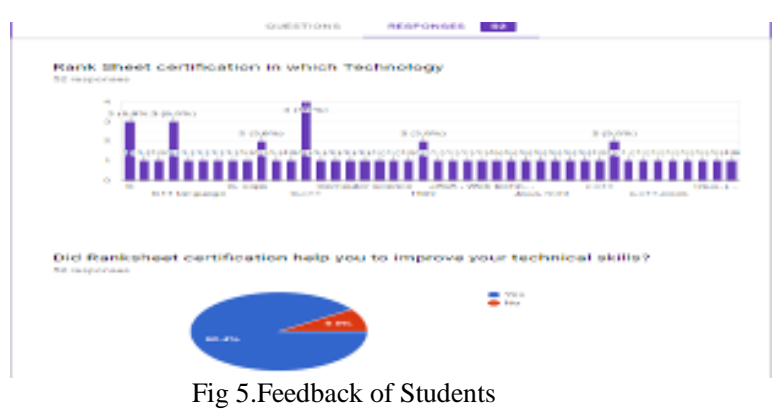

\section{Conclusion}

Certifications have changed the way of learning of students. This certifications play a major role in Outcome Based education. It helps to improve the quality of education if added in the regular curriculum of the University.

\section{Acknowledgement}

We gracefully acknowledge the colleagues who supported us to complete the paper. This work is supported by Head of the Department.We thank all who have extended their support to bring out this paper.

\section{References}

Surendar Rawat , Shruti Karkare ,Electronics and Communication Technology Department, V. E. S. Polytechnic, Sindhi Society, Chembur, Mumbai, India, An Empirical Study on Assessment of PO Attainment for a Diploma Program, International Journal of Advanced Research in Engineering and Technology ,(IJARET) Volume 6, Issue 11, Nov 2015.

Zamri Mohamed, Mohd Yusof Taib, M.S. Reza,Malaysian Technical Universities, Assessment Method for Course Outcome and Program Outcome in Outcome Based Education (OBE), Conference on Engineering and Technology, June 28-29, 2010, Bayview Hotel, Melaka, Malaysia.

Self Assessment Report (SAR) format diploma engineering programs from National Board of Accreditation.

National Board of Accreditation Manual for Diploma Engineering Programmes (Tier-II).

"Extending India"s leadership in the global IT and BPO industries" - NASSCOM-McKinsey Report published in 2005 